ORIGINAL ARTICLE

\title{
Signs and symptoms of illness in early infancy: associations with sudden infant death
}

\author{
M Wailoo, J R Thompson, A J Waite, R C Coombs, J A Jackson
}

See end of article for authors' affiliations

\section{Correspondence to:} Dr MWailoo, Department of Child Health, Clinical Sciences Building, Leicester Royal Infirmary, Leicester LE2 7LX, UK: mw33@le.ac.uk

Accepted 1 March 2003

\begin{abstract}
Aims: to describe a pattern of illness in "normal" infants, and to assess to what extent this may differ in infants who die suddenly and unexpectedly.

Methods: All infants are on the CONI (Care of the Next Infant) scheme in which mothers record symptoms and signs of illness prospectively, on a daily basis from birth to approximately age 6 months. The symptoms of infants who die suddenly and unexpectedly are compared with those of a consecutive sample of infants who survive. Twenty one babies died suddenly, of whom 11 were cot deaths and 10 had "known causes" of death. Ninety eight infants who survived were used as consecutive controls. Prospective daily records of the presence or absence of 26 signs and symptoms were kept by all of the mothers, commencing at birth and lasting an average of 176 days in survivors; 84 days in SIDS; and 93 days in infants who died of known causes.

Results: Standardised for age and the time of year, on any given day, the mothers of the SIDS infants were over eight times more likely to record their child as being pale, six times more likely to be sweating, and twice as likely to be irritable. Other signs and symptoms which were three times more likely to be recorded were sore gums, dry stools, and coldness. Infants who died of known causes generally had fewer symptoms.

Conclusions: Cot death infants have a range of symptoms which appear to be of a general nature, and not related to any one system. Symptoms are seen throughout life and not related to the time of death.
\end{abstract}

$\mathrm{N}$ ewborn infants are at their most vulnerable during the first six months of life, when death ${ }^{1}$ and illness ${ }^{2}$ are more likely to occur. Inherent physiological factors are undoubtedly important as infants adapt to their new environment and confront some infections for the first time. However, some illnesses are seasonal, ${ }^{3}$ with winter presenting new challenges such as respiratory syncytial infection. ${ }^{4}$ $\mathrm{CESDI}^{5}$ reports a clear temporal association between illness and death, particularly sudden infant death in infancy, which still remains the commonest type of death despite a recent fall. $^{6}$

Most studies of illness in children who have died unexpectedly have had to rely on retrospective data that may be unreliable, especially if a period of more than a few weeks had elapsed since death. The Care of the Next Infant (CONI) scheme provides prospective morbidity data on infants born after a sibling cot death. A small proportion of the mothers who participated in CONI went on to experience a second cot death. The prospective records kept by those mothers provide a unique view of the signs and symptoms of illness experienced prior to a cot death.

\section{METHODS}

The CONI scheme assists in the provision of support for new parents who have experienced the cot death of a previous child. ${ }^{7}$ Parents are approached during the pregnancy and offered weekly visits from their health visitor and access to the paediatrician. In addition to advice and support the parents are offered resuscitation training, an apnoea monitor, scales for recording weight, and a daily symptom diary. Parents stay on the CONI programme for six months or until two months after the age at which their previous child died.

The symptom diary is a chart that includes 26 signs and symptoms, plus details of medications, immunisations, weight, and number of triggered apnoea alarms. The signs and symptoms form the basis for discussion with the health visitor during the weekly visit. In the early years of the CONI programme $91 \%$ of parents chose to complete the diary, although in some cases the completeness with which they filled in the charts was thought to diminish as the parents' anxiety reduced. ${ }^{8}$ Mothers only recorded symptoms on the day observed.

Daily symptom diaries of the live infants were used to calculate the proportions of days when each sign or symptom was recorded in a table of age (in intervals of 30 days) by time of year (in four seasons). For each of the sudden infant death syndrome (SIDS) infants the rates from the control infants were applied to the corresponding age and season for each day when the SIDS infant was alive in order to calculate the expected number of days on which the symptom would be recorded. The expected number was compared with observed number to give a standardised morbidity ratio (SMR) for that infant. Summing the expected and observed numbers and then forming their ratio gave the overall SMR for the group of all SIDS infants.

In order to assess the significance of the SMRs of a particular child they were compared with corresponding ratios calculated by taking the same age range for any of the control infants whose diary included the whole length of the SIDS infant's life. The proportion of control infants gave a more extreme SMR was noted. To assess the significance of the overall SMRs, a random sample of control infants who had been observed over the same age ranges as the SIDs infants was selected. The overall SMR was calculated for that sample of control infants and the sampling process was repeated 1000 times. The proportion of samples that gave a

Abbreviations: CONI, Care of the Next Infant scheme; SIDS, sudden infant death syndrome; SMR, standardised morbidity ratio 
Table 1 Mean (range) of the ages in days when the periods of monitoring started and finished and the length of the recording period

\begin{tabular}{llccc}
\hline & Sample size & First recording & Last recording & Length of recording \\
\hline Survivors & 98 & $9(1-72)$ & $184(31-403)$ & $176(22-347)$ \\
SIDS & 11 & $11(1-26)$ & $94(13-195)$ & $84(8-179)$ \\
Other deaths & 10 & $7(1-16)$ & $99(19-283)$ & $93(14-268)$ \\
\hline
\end{tabular}

more extreme SMR was noted and gave the $\mathrm{p}$ values shown in table 2 .

\section{RESULTS}

Data from 21 babies who had died while under the CONI scheme and 98 consecutive controls were compared. Eleven of the deaths had been classified as SIDS; of the remainder, four were associated with respiratory conditions, one with a metabolic disorder, three with violence, and two with uncertain causes.

Table 1 shows the length of recording available for each child. In accordance with the aims of the CONI scheme the infants had diaries kept for about six months. The SIDS cases and the other deaths had diaries kept on average for about three months.

Table 2 lists 26 of the signs and symptoms recorded in the CONI diary. For each child, data were extracted for the first 90 days or until death or the end of recording if that was sooner; the first three columns of data show the percentage of days during this period on which each symptom was recorded.

For each symptom in the live infants we calculated rates of recording by age and season of the year. Ages were divided into six bands, each of 30 days and four seasons were calculated based on the day of the year. The rates were used to calculate the expected number of diary entries for each child that died given the period over which their diary was completed. The standardised morbidity ratios are shown in table 2 along with their simulated significance levels.

In the SIDS comparisons of table 2, the features that stand out are the high frequency with which mothers recorded that there child was pale ( SMR 840, $\mathrm{p}=0.03$ ) and sweating ( SMR $612, p=0.07)$. Also noticeably higher than expected were sore bottom(SMR 227, p=0.08), dry bowel (SMR 336, $\mathrm{p}=0.08)$, and feeling cold (SMR 318, p=0.14), while eczema (SMR 33, p = 0.02) was recorded much less. Irritability was only twice as common in the SIDS infants, but due to the consistency of the increase across the 11 SIDS infants, this increase was statistically significant $(p=0.03)$. Wheeze and cough were a little more common in the SIDS cases than the controls, but not remarkably so, and snuffles were less common than might have been expected.

In the other deaths very few symptoms were more common than expected and several were recorded at extremely low rates. This may reflect poor recording of minor symptoms in children who were either known to have a major illness or who were subject to neglect.

The CONI mothers were also offered apnoea alarms that they could use to warn them if their child paused breathing while asleep and scales so that they could record their babies' weight changes. Table 3 shows the data for the days on which the apnoea alarm was triggered. The rates in the SIDS infants were very similar to those in the controls and the rates in the other deaths group were extremely low.

Table 2 Morbidity as recorded by the CONI mothers

\begin{tabular}{|c|c|c|c|c|c|c|c|}
\hline \multirow[b]{2}{*}{ Signs and symptoms } & \multicolumn{3}{|c|}{$\begin{array}{l}\% \text { days when recorded: birth to } 90 \text { days, death, or end of } \\
\text { recording }\end{array}$} & \multicolumn{4}{|c|}{ Morbidity ratios* } \\
\hline & Survivors $(\mathrm{n}=98$ ) & SIDS $(n=11)$ & Other deaths $(n=10)$ & SIDS & p valuet & Other deaths & $\mathrm{p}$ valuet \\
\hline Snuffles & 22 & 18 & 24 & 64 & 0.08 & 88 & 0.63 \\
\hline Ruttling & 7 & 5 & 5 & 56 & 0.10 & 50 & 0.17 \\
\hline Wheeze & 5 & 19 & 4 & 268 & 0.16 & 43 & 0.30 \\
\hline Cough & 11 & 20 & 15 & 133 & 0.34 & 80 & 0.35 \\
\hline Turn & 1 & 1 & 0 & 144 & 0.42 & 14 & 0.00 \\
\hline Oral thrush & 5 & 5 & 14 & 110 & 0.62 & 141 & 0.50 \\
\hline Sore gums & 1 & 10 & 1 & 321 & 0.23 & 77 & 0.43 \\
\hline Colic & 19 & 34 & 7 & 192 & 0.24 & 29 & 0.00 \\
\hline Refused feed & 1 & 1 & 1 & 150 & 0.30 & 60 & 0.39 \\
\hline Reduced feed & 6 & 8 & 5 & 124 & 0.30 & 62 & 0.25 \\
\hline Thirsty & 2 & 4 & 1 & 229 & 0.30 & 84 & 0.13 \\
\hline Vomit & 8 & 10 & 5 & 132 & 0.48 & 61 & 0.13 \\
\hline Drier bowel & 3 & 8 & 4 & 336 & 0.08 & 120 & 0.59 \\
\hline Loose bowel & 8 & 8 & 8 & 100 & 0.58 & 81 & 0.18 \\
\hline Irritable & 9 & 16 & 13 & 199 & 0.03 & 152 & 0.34 \\
\hline Sleepy & 2 & 3 & 0 & 139 & 0.27 & 11 & 0.00 \\
\hline Different cry & 2 & 4 & 4 & 135 & 0.46 & 192 & 0.44 \\
\hline Sore bottom & 8 & 17 & 9 & 227 & 0.08 & 199 & 0.09 \\
\hline Eczema & 10 & 5 & 7 & 33 & 0.02 & 41 & 0.00 \\
\hline Rash & 10 & 17 & 1 & 197 & 0.11 & 10 & 0.00 \\
\hline Stick eye & 9 & 7 & 2 & 80 & 0.33 & 19 & 0.00 \\
\hline $\mathrm{Hot}$ & 1 & 2 & 0 & 172 & 0.33 & 19 & 0.00 \\
\hline Cold & 0 & 1 & 1 & 318 & 0.14 & 405 & 0.17 \\
\hline Sweating & 1 & 5 & 1 & 612 & 0.07 & 229 & 0.28 \\
\hline Pale & 1 & 7 & 0 & 840 & 0.03 & 100 & 0.32 \\
\hline Not self & 4 & 7 & 4 & 194 & 0.13 & 149 & 0.46 \\
\hline
\end{tabular}


Table 3 Apnoea alarms; shows the number of days in which the alarm was recorded as having "gone off"

\begin{tabular}{llllllll}
\hline $\begin{array}{l}\text { \% days when recorded: birth to } 90 \text { days, death or } \\
\text { end of recording }\end{array}$ & & & & & & & \\
Morbidity ratios*
\end{tabular}

Table 4 shows the average weight gains per week based on the difference between the last weight recorded and the first weight recorded. For comparison the average overall controls who had weights recorded over a similar period was also calculated. Comparing the weight change in the child that died with the average of eligible controls, the SIDS children put on slightly more weight than expected, but the variability was too large for any conclusions to be drawn. Three of the other deaths did not have two recorded weights from which the weight change could be calculated, and although these children showed lower than expected weight gains, the variability was such that in this sample size no conclusions could be drawn.

As a proxy for birth weight we took the first recorded weight in each of the SIDS deaths; these were measured between day $\mathrm{l}$ and day 28 . For comparison we averaged the control babies who were weighed within a week of the age of the SIDS infant when he or she was first weighed. On average the SIDS infants were $738 \mathrm{~g}$ lighter than the corresponding average for controls; five of the 11 infants were more than $1000 \mathrm{~g}$ lighter. These data show that the SIDS infants tended to be small, which may contribute to their increased number of symptoms.

\section{DISCUSSION}

Parents on the CONI scheme, having had a cot death, are likely to be keen and fastidious in baby care, and careful in recording baby's symptoms-the quality and accuracy of these data may, therefore, be more precise and accurate than in other studies. Symptoms of illness in babies and infants have generally been reported retrospectively; therefore, the accuracy of the data may be tainted by recall bias, particularly that in relation to cot death.

Stanton and colleagues, ${ }^{9}$ Wilson and colleagues, ${ }^{10}$ and Thornton and colleagues ${ }^{11}$ have all assessed symptoms of acute illness in infants, and have identified a wide variety of symptoms which closely resemble those seen in this study. Cold extremities, noisy breathing, and irritability are all common in infants generally, but symptoms such as wheezing and cough predominate, perhaps as a result of

Table 4 Average (SD) weight change per week averaged over the life of the infant who died and the same ages for the comparable controls

\begin{tabular}{|c|c|c|c|c|}
\hline & \multirow[b]{2}{*}{ No. } & \multirow{2}{*}{$\begin{array}{l}\text { Weekly weight } \\
\text { change } \\
\text { Mean }\end{array}$} & \multicolumn{2}{|c|}{ Difference } \\
\hline & & & Mean & SD \\
\hline $\begin{array}{l}\text { SIDS } \\
\text { All matched controls } \\
\text { Other deaths } \\
\text { All matched controls }\end{array}$ & 11 & $\begin{array}{l}240 \mathrm{~g} \\
205 \mathrm{~g} \\
194 \mathrm{~g} \\
213 \mathrm{~g}\end{array}$ & $\begin{array}{r}35 g \\
-19 g\end{array}$ & $62 \mathrm{~g}$ \\
\hline
\end{tabular}

the medicalisation of the data collection. Stanton, ${ }^{9}$ and more recently CESDI, ${ }^{5}$ specifically studied cot deaths, albeit retrospectively, and then only symptoms in the period immediately prior to death. Major symptoms were common terminally, but half of these were non-specific; all were present several days before death. There is an implication that these deaths are probably preventable, though the wide range of symptoms, with many being non-specific, reduces their predictive value.

The modest number of cot deaths in this study does not allow for extravagant claims, as it reduces the power of the study and does not allow for any further categorisation of symptoms. The significance of these findings must therefore be treated cautiously. However, by its prospective nature, covering the period from birth to death, and not confined to the week or so just prior to death, the study can justify a claim to providing a unique and accurate picture of the morbidity pattern of the entire life of these infants.

The predominant symptoms in this study, particularly in the cot deaths, are pallor, sweating, irritability, and being cold; they differ from a similar prospective study by Holme, ${ }^{12}$ in which snuffles, wheezing, and cough were most commonly reported, using diary cards from which a choice from only 15, mainly clinical symptoms were offered compared to 26 in this study. This may account for the greater emphasis on behavioural symptoms here, many of which were not included in Holme's study.

The value of symptoms as precursors to serious illness, or as predictors of cot death is only small, as many infections have clinically similar incubation and prodromal phrases, and the heterogeneity of SIDS suggests a variable vulnerability to infection irrespective of the severity of the outcome. However, as the cot death infants in this study were more likely to be irritable, cold, pale, and sweaty, these symptoms may be indicative of a widespread pathophysiological, response, not confined to any one system-perhaps the result of a sensitive and over-responsive autonomic nervous system.

\section{ACKNOWLEDGEMENTS}

We thank The Foundation for the Study of Infant Deaths for the use of CONI data.

\section{Authors' affiliations}

M Wailoo, J A Jackson, Department of Child Health, University of Leicester, UK

J R Thompson, Department of Epidemiology and Public Health, University of Leicester, UK

A J Waite, Academic Unit of Child Health, University of Sheffield, UK R C Coombs, Sheffield Children's Hospital, UK

\section{REFERENCES}

1 HMSO. Report of the Chief Medical Officer's Expert Group on the Sleeping Position of Infants and Cot Deaths. London: HMSO, 1993.

2 Valman HC. The first year of life, 4th edn. London: BMJ Publishing Group, 1995. 
3 Golding J, Limerick S, MacFarlane A. Sudden infant death: patterns, puzzles and problems. Shepton Mallet: Open Books, 1985.

4 Cubie HA, Duncan LA, Marshall LA, et al. Detection of respiratory syncytial virus mucluc acid in archival post mortem tissue from infants. Paediatr Pathol Lab Med 1997;17:927-38.

5 DoH. Confidential enquiry into still births and deaths in infancy, 3rd Annual Report. London: Department of Health, 1994

6 Court C. Cot deaths: Britain. Incidence reduce by two thirds in five years. BMJ 1995;310:7-8.

7 McKenzie A, Waite AJ. The CONI Project: parents' evaluation of the care provided to the first 2000 babies. Health Visitor 1995;68:239-40.
8 Waite A McKenzie, Carpenter R. Report on 5000 babies using the CONI (Care of Next Infant) programme. London: The Foundation for the Study of Infant Deaths, 1998

9 Stanton AN, Downham MAPS, Oakley JR, et al. Terminal symptoms in children dying suddenly and unexpectedly at home. BMJ 1978:2:1249-51.

10 Wilson A, Downham MAPS, Foster DP. Acute illness in infants: a general practice study. J R Coll Gen Pract 1984:155-9.

11 Thornton AJ, Morley CJ, Fowler MA. Symptoms in 298 infants under 6 months old, seen at home. Arch Dis Child 1990;65:280-5.

12 Holme CO. Incidence and prevalence of non-specific symptoms and behavioural changes in infants under the age of 2 years. Br J Gen Pract 1995;45:65-9.

\section{ARCHIVIST}

\section{Nailfold capillary microscopy}

$M$ icroscopic examination of nailfold capillaries is accepted as an investigational tool for adults with connective tissue diseases. Abnormalities are found in more than $80 \%$ of adult patients with scleroderma or related disorders. There are fewer data about children but workers in Birmingham (P Dolezalova and colleagues. Annals of the Rheumatic Diseases 2003;62:444-9) have described their findings in healthy adults and children and in children with rheumatic diseases.

They performed nailfold capillary microscopy (nailfold capillaroscopy, NFC) using a stereomicroscope with fibre optic illumination. Images were enlarged 66 times $(3 \mathrm{~mm}$ section of nailfold magnified to $19.8 \mathrm{~cm}$ on screen) and photographed using a colour digital video camera. Six parameters were assessed: capillary density, loop width, tortuosity, avascularity, disarrangement, and number of abnormal vessels. They examined 18 healthy children aged 2-18 years (mean 7 years), 20 healthy adults, 15 children with juvenile idiopathic arthritis, 18 with connective tissue diseases (juvenile dermatomyositis, systemic sclerosis, mixed connective tissue disease, or overlap syndromes), eight with systemic lupus erythematosus, nine with primary Raynaud's syndrome, and three with vasculitis.

Healthy children had fewer and wider capillary loops than healthy adults, linear capillary density increasing gradually with age. Median capillary density was 6.7 capillaries per mm in children and 8.9 capillaries per mm in adults. Median capillary loop width was $47 \mu \mathrm{m}$ (children) versus $41 \mu \mathrm{m}$ (adults). Children with connective tissue diseases had fewer (4.9/ $\mathrm{mm}$ ) and broader $(162 \mu \mathrm{m})$ capillary loops. Morphologically abnormal capillaries (at least two abnormal capillaries on at least two of eight fingers (not thumbs) examined) were found in 11 of the 18 children with connective tissues diseases but in no other children. These changes were most marked in children with dermatomyositis. Children with connective tissue diseases also had a greater degree of avascularity and general disarrangement of capillary pattern. Findings were, on the whole, normal in children with juvenile idiopathic arthritis, systemic lupus erythematosis, or Raynaud's syndrome.

Nailfold capillary microscopy may provide useful information to aid the diagnosis of connective tissue diseases in children.

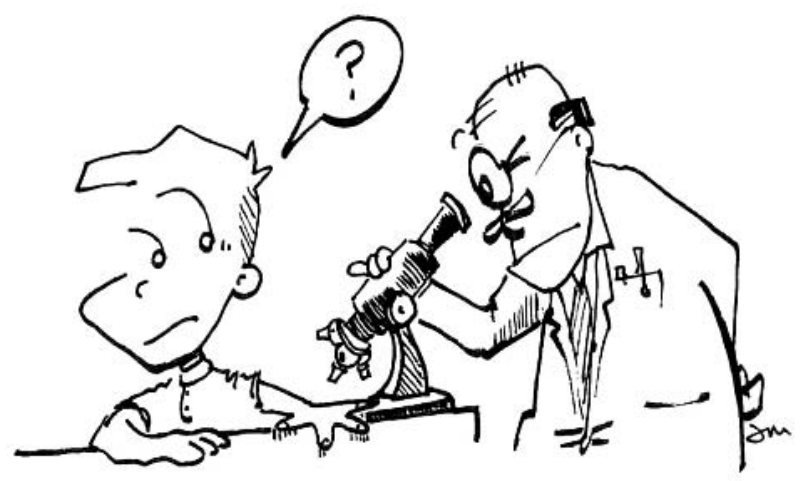

Illustration by Jack Maypole, MD 